\title{
Antoine VAUCHEZ, 2014, Démocratiser l'Europe, Paris, Seuil, « La République des idées », 97 p.
}

\section{Olivia Leboyer}

\section{(2) OpenEdition}

1 Journals

Édition électronique

URL : http://journals.openedition.org/ress/2902

DOI : $10.4000 /$ ress.2902

ISSN : 1663-4446

Éditeur

Librairie Droz

\section{Édition imprimée}

Date de publication : 27 novembre 2014

Pagination : 260-262

ISBN : 978-2-600-01866-1

ISSN : 0048-8046

\section{Référence électronique}

Olivia Leboyer, « Antoine VAUCHEZ, 2014, Démocratiser l'Europe, Paris, Seuil, « La République des idées », 97 p. », Revue européenne des sciences sociales [En ligne], 52-2 | 2014, mis en ligne le 20 novembre 2014, consulté le 22 septembre 2020. URL : http://journals.openedition.org/ress/2902 ; DOI : https://doi.org/10.4000/ress.2902

Ce document a été généré automatiquement le 22 septembre 2020.

(c) Librairie Droz 


\title{
Antoine VAUCHEZ, 2014, Démocratiser l'Europe, Paris, Seuil, «La République des idées », 97 p.
}

\author{
Olivia Leboyer
}

1 En 2013, dans L'Union par le droit: l'invention d'un programme institutionnel pour l'Europe (Paris, Presses de Sciences Po), Antoine Vauchez soulignait l'existence d'une "Communauté de droit», constituant le point d'ancrage d'une multiplicité d'investissements différenciés dans l'institutionnalisation d'un ordre politique européen. C'était une nouvelle métaphysique de l'Europe, construite par petites touches, à partir des points de vue croisés des institutions, qu'il s'agissait ainsi de mettre en lumière. Avant même d'être une œuvre économique, les Communautés européennes originaires (la CECA, la CEE et la CEEA) pouvaient être appréhendées comme une version communautaire de l'État de droit. L'analyse n'avait rien de normatif, mais s'attachait à saisir les rouages et la logique d'une entreprise collective. Paru en février 2014, le nouvel essai d'Antoine Vauchez, au titre plus percutant, Démocratiser l'Europe, propose de nouvelles pistes de réflexion.

2 Le constat est simple: l'Europe connaît une crise démocratique. Les résultats des dernières élections parlementaires européennes en témoignent. Les responsables des partis politiques européens peinent encore à éveiller, chez les citoyens, un sentiment d'appartenance. Comment démocratiser l'Europe ? C'est cette question pratique que l'auteur soulève. En premier lieu, le sentiment de distance éprouvé par les citoyens tient à une difficulté à se représenter l'Europe telle qu'elle est, conditionnés qu'ils sont par les catégories de la politique nationale. La représentation n'est pas la même au niveau européen, où les lieux vides du pouvoir ne favorisent pas la constitution d'une élite politique clairement identifiable. "Les partis politiques européens", "le Parlement européen ", " la citoyenneté » ou encore "la démocratie représentative » sont certes des concepts séduisants, mais ils peinent à décrire précisément la réalité européenne. Or, si les outils linguistiques sont inadéquats, c'est toute la réflexion qui se trouve bloquée. Aussi est-il indispensable de saisir au plus juste les logiques de la 
construction européenne. Pour l'auteur, ce n'est pas du seul Parlement que viendra la démocratisation de l'Europe. Ce n'est pas non plus l'opération électorale à elle seule qui garantit automatiquement la légitimité. La Cour de justice, la Commission européenne et la Banque centrale -institutions indépendantes sans doute moins connues des citoyens -, constituent aussi un relais essentiel dans l'expression de l'intérêt général. C'est ce triptyque d'institutions indépendantes, laissées jusqu'à présent dans l'angle mort de l'analyse, que l'ouvrage nous invite à considérer avec une attention nouvelle.

Intitulé « Une démocratie Potemkine? », le premier chapitre entend montrer qu'il faut se garder d'appréhender l'Europe sous le seul prisme avantageux de la démocratie représentative. La métaphore des façades russes en carton-pâte éclaire le danger qu'il y a à employer des concepts creux. User d'une rhétorique séduisante mais sans rapport direct avec la réalité de l'Europe ne peut qu'entretenir la confusion. Et reprendre la terminologie servant à désigner les institutions nationales constitue une solution de facilité qui contribue à donner de l'Europe une image déformée.

4 Le second chapitre, "l'Europe entre indépendance et expertise ", s'attache à décrire la polis européenne, dont l'existence doit beaucoup à des institutions clés : la Cour de justice, l'Administration, la Banque centrale, entre autres agences de régulation. Moins emblématiques que le Parlement ou la Commission, ces institutions n'en jouent pas moins un rôle capital. Leur fonctionnement a permis l'émergence d'un nouveau type de légitimité politique, extérieur au lien électoral comme aux passions partisanes. Le régime politique européen ne peut en effet se réduire à la projection des démocraties nationales. C'est avec la mise en place du Marché commun, au carrefour des décisions de la Cour de justice et des règlements administratifs de la Commission, qu'une autorité politique européenne est née. Par leur indépendance et leur expertise, ces institutions deviennent de fait la matrice d'un nouveau type de légitimité politique. Dès son avènement, l'Europe s'est construite selon une politique du Marché commun rythmée par les avancées de la Cour ou de la Commission. L'idée européenne se déploie ainsi sur un temps long, qui n'est pas réductible aux calendriers électoraux. Pour l'auteur, c'est aux trois institutions indépendantes d'inventer le nouveau lexique de la légitimité politique européenne. Il s'agit là, pour la Cour de justice, la Commission européenne et la Banque Centrale Européenne, d'un véritable mandat impératif, fondé sur l'indépendance statutaire de ces institutions. N'étant pas liées par la politique diplomatique et partisane, elles se rapprochent de l'esprit communautaire des Pères fondateurs. Une légitimité acquise par l'expertise, et non par l'élection, produit ainsi de nouveaux types de serviteurs de l'Europe, comme le banquier européen. Il y a là une autre approche de la légitimité, qui s'arc-boute sur les concepts de compétence et de raison.

5 Le troisième chapitre, "La crise d'indépendance de l'Europe ", souligne la responsabilité de plus en plus décisive qui incombe à ces nouvelles élites, à la tête des trois institutions indépendantes. En pleine crise de la zone euro, c'est ainsi au président de la Cour de justice, Vassilio Skouris, et à l'ancien vice-gouverneur de la BCE, Lucas Papademos, qu'il est revenu la tâche essentielle de rétablir la confiance, et non à un dirigeant politique comme le premier ministre grec Georges Papandréou, lequel s'était montré impuissant. Ces nouvelles élites voient leur autorité renforcée par les conditions de nomination de leurs membres. Fruits d'équilibres politiques et géopolitiques, elles satisfont au besoin de représentativité. D'une certaine manière, les trois institutions indépendantes possèdent donc bien une dimension politique. Il n'est 
pas jusqu'à leurs domaines d'intervention qui témoignent de leur poids politique respectif. La Cour, la Banque centrale et la Commission ont pesé sur des questions qui relevaient classiquement des compétences exclusives des États, comme le budget ou le droit du travail. Ou plus précisément, elles n'ont pas eu à affronter de contrepoids. Dès lors, leurs compétences ont connu un accroissement constant. Peut-on, pour autant, parler d'un gouvernement des juges? Paradoxalement, le rôle politique des trois institutions indépendantes se trouve bloqué par certaines initiatives, comme le Traité de Lisbonne qui réduit pourtant le contrôle exercé par les États sur les procédures de nomination des juges et des banquiers centraux. Pour l'auteur, cette nouvelle élite européenne, dont les membres pourraient apparaître en hommes d'États providentiels, fait plutôt l'objet d'un déni. La dimension politique des trois institutions indépendantes n'est pas suffisamment reconnue. Tout se passe comme si l'on avait enveloppé ces institutions d'une "cape d'invisibilité politique» (p.62). Or, insister sur la dimension technique et apolitique de ces institutions, comme le font à l'envi les médias, reviendrait à les présenter comme une sorte d'élite saint-simonienne, détachée des attaches politiques. La réalité est tout autre. Les États ont en effet conservé le monopole de la nomination de leurs juges, banquiers et commissaires.

6 Le quatrième chapitre reprend le titre de l'ouvrage, "Démocratiser l'Europe ». Le constat dressé, il s'agit de passer aux prescriptions. La citoyenneté européenne, les droits fondamentaux ou encore les valeurs européennes, sont autant de questions qui dépendent désormais étroitement de la Commission, de la Cour de justice et de la BCE, et qui semblent bien constituer la clé de voûte de l'Union européenne. Comment les faire entrer, de manière visible, dans le champ politique? Dorénavant, l'importance politique des décisions en matière judiciaire, administrative et monétaire ne saurait être occultée. C'est bien un mandat politique qu'il revient aux trois institutions d'assumer. Pour définir précisément ce mandat, les communautés savantes ont un rôle à jouer. Les Livres blancs, produits en abondances, doivent ainsi être lus avec une attention critique. Enfin, il importe de mettre en évidence la dimension représentative des trois institutions indépendantes, qui ne peuvent être réduites à leurs seuls aspects techniques. Pourquoi n'y aurait-il pas, au sein de ces institutions, des représentants des syndicats? Sur le plan international, la question d'une meilleure représentativité se pose également. Ainsi des débats sur la parité au sein de la Cour pénale internationale. S'interroger sur les conditions d'une plus grande représentativité, sexuelle comme socio-professionnelle, de ces institutions, permettrait de renforcer la légitimité de l'Union européenne. Il s'agit, au-delà, de réfléchir au contenu de cet intérêt général qu'il revient à l'Europe d'incarner.

7 Entre indépendance et expertise, ce trio institutionnel ne conduirait pas à une Europe comme «lieu vide» du politique, mais permettrait d'établir un jeu concurrentiel d'institutions porteuses de légitimités plurielles. Ces institutions indépendantes ne devraient d'ailleurs pas renoncer à la représentativité, bien au contraire. Pour incarner l'esprit européen, le pluralisme et l'ouverture seraient les meilleurs garants. Si l'Union européenne s'est en grande partie construite par le droit, son fondement demeure d'ordre spirituel. 


\section{AUTEURS}

OLIVIA LEBOYER

IEP de Paris - PACTE 